\title{
Short-Term Effects of Ambient Air Pollution On Daily Emergency Room Visits for Abdominal Pain: A Time- Series Study in Wuhan, China
}

\author{
Yaqi Liu \\ Wuhan University Zhongnan Hospital \\ Yi Jiang \\ Wuhan University Second Clinical College: Wuhan University Zhongnan Hospital \\ Manyi Wu \\ Wuhan University Second Clinical College: Wuhan University Zhongnan Hospital \\ Sunghar Muheyat \\ Wuhan University Second Clinical College: Wuhan University Zhongnan Hospital \\ Dongai Yao \\ Wuhan University Zhongnan Hospital \\ Xiaoqing Jin ( $\square$ redjin@whu.edu.cn ) \\ Wuhan University Zhongnan Hospital
}

\section{Research Article}

Keywords: Air pollution, Abdominal pain, Emergency room visits, Time-series study

Posted Date: September 14th, 2021

DOI: https://doi.org/10.21203/rs.3.rs-866657/v1

License: (c) (i) This work is licensed under a Creative Commons Attribution 4.0 International License. Read Full License 


\section{Abstract \\ Background}

There are few studies focused on the correlations between ambient air pollution and abdominal pain, especially in emergency departments in China.

\section{Method:}

Daily data (from January 1, 2016 to December 31, 2018), including air pollution concentration $\left(\mathrm{SO}_{2}, \mathrm{NO}_{2}, \mathrm{PM}_{2.5}, \mathrm{PM}_{10}\right.$, $\mathrm{CO}$, and $\mathrm{O}_{3}$ ) and meteorological variables, for daily emergency room visits (ERVs) were collected in Wuhan, China. We conducted a time-series study to investigate the potential correlation between six ambient air pollutants and ERVs for abdominal pain and their effects, in different genders, ages and seasons.

\section{Results}

A total of 16,306 abdominal pain ERVs were identified during the study period. A $10-\mu \mathrm{g} / \mathrm{m}^{3}$ increase in concentration of $\mathrm{SO}_{2}, \mathrm{NO}_{2}, \mathrm{PM}_{2.5}, \mathrm{PM}_{10}, \mathrm{CO}$, and $\mathrm{O}_{3}$ corresponded respectively to incremental increases in abdominal pain of $6.12 \%$ (95\% confidence interval [Cl]: -0.44-13.12), 1.65\% (95\%Cl: -0.25-3.59), 1.12\% (95\% Cl: -0.18-2.44), 0.38\% (95\%Cl: -1.091.87), 9.87\% (95\% Cl:3.14-17.05) and 1.11\% (95\% Cl: $0.03-2.21)$. We observed significant correlations between $\mathrm{CO}$ and $\mathrm{O}_{3}$ and daily abdominal pain ERVs increase, and positive but insignificant correlations between the other pollutants and ERVs. The effects were stronger mainly for females (especially $\mathrm{SO}_{2}$ and $\mathrm{O}_{3}$ ) and younger people (especially $\mathrm{CO}$ and $\mathrm{O}_{3}$ ). The correlations of $\mathrm{PM}_{2.5}$ and $\mathrm{PM}_{10}$ were stronger in cool seasons, while the correlation of $\mathrm{CO}$ was stronger in warm seasons.

\section{Conclusion}

Our time-series study suggested that short-term exposure to air pollution (especially $\mathrm{CO}$ and $\mathrm{O}_{3}$ ) was positively correlated with ERVs for abdominal pain in Wuhan, China, and that their effects varied by season, gender and age. These data can add evidence on how air pollutants affect the human body, and may prompt hospitals to take specific precautions on polluted days and maintain order in emergency departments made busier due to the pollution.

\section{Introduction}

The Global Burden of Disease study identified air pollution as a leading cause of global disease burden, especially in developing countries.(Collaborators 2018) Short-term exposure to ambient air pollution can acutely deteriorate respiratory, cardiovascular and digestive diseases, leading to increased emergency room visits (ERVs).(Rodopoulou, Samoli et al. 2015, Al Ahad, Sullivan et al. 2020, Vignal, Guilloteau et al. 2021) Since Wuhan is one of the twenty most polluted cities with a large number of daily ERVs in China, which is the biggest developing country in the world, it is important to figure out potential health risks from ambient air pollution.

Recently, there has been an accumulation of articles revealing the effects of air pollution on emergency departments, (Rodopoulou, Samoli et al. 2015, Chen, Zheng et al. 2019) which plays a significant role in dealing with public health events, meeting the needs of patients and improving the treatment success rate. However, overcrowding of emergency 
departments is an international issue, among which abdominal pain is the most significant proportion.(Hooker, Mallow et al. 2019) The most common diseases manifesting abdominal pain in ERVs are gastroenteritis, cholecystitis, and urolithiasis which will cause acute and serve pain thus need emergency treatments. Environmental pollution has been noted to play an important role in the development of these diseases. For instance, exposure to the particulate matter may lead to urolithiasis increase, by causing urine volume decreases through vascular endothelial injury, systemic inflammation, atherosclerosis and microvascular changes.(Sun, Wang et al. 2005, Chow, Watson et al. 2006) Air pollution exposure can increase the hospitalizations for digestive diseases, including inflammatory bowel disease, peptic ulcers, and enteritis,(Ananthakrishnan, McGinley et al. 2011, Xu, Kan et al. 2016, Tsai, Chiu et al. 2019, Gu, Shi et al. 2020) although the mechanisms remain unclear and inconclusive. However, studies focus the pollution effects on specific diseases or symptoms in ERVs, such as abdominal, are still lacking. It will be favorable for hospitals to figure out the correlations between air pollution and abdominal pain, and thereby to understand the characteristics of ERVs, take precautions and maintain order in specific and heavy polluted days.

Considering the above-mentioned, we conducted this time-series study to analyze the correlations between six ambient air pollutants $\left(\mathrm{SO}_{2}, \mathrm{NO}_{2}, \mathrm{PM}_{2.5}, \mathrm{PM}_{10}, \mathrm{CO}, \mathrm{O}_{3}\right)$ and ERVs for abdominal pain, in Zhongnan Hospital of Wuhan University from 1 January 2016 to 31 December 2018. We also analyzed the discrepancy correlation between different seasons, gender and age. In addition, we explored the exposure-response relationship curves between ERVs for abdominal pain and air pollutants, as well as the co-effects among six air pollutants. It should be useful in risk assessment, resources allocation and health policy making.

\section{Materials And Methods}

Wuhan is the capital of Hubei Province, with a population size over 10 million, and lying in Central China (latitude $30^{\circ} 35^{\prime} \mathrm{N}$ and longitude $114^{\circ} 17^{\prime} \mathrm{E}$ ), and covering $8494.41 \mathrm{~km}^{2}$. It consists of seven central districts, and six suburban and rural districts (Fig. 1). Because it is an essential industrial and transport interchange of China, the main causes of air pollution are vehicle exhaust, coal-fired heating, and industrial emissions.(Ren, Li et al. 2017) Wuhan has a humid monsoon subtropical climate. Summers are hot and wet while winters are cold and dry. The average temperature is $29^{\circ} \mathrm{C}$ in July and $4^{\circ} \mathrm{C}$ in January.

\section{Emergency room visits data}

We were provided with the daily number of ERVs from January 1, 2016 to December 31, 2018, from Zhongnan Hospital of Wuhan University in Wuhan, China. A doctor's team discussed the disease diagnoses, corrected them to standard names, and re-matched them to an accurate International Classification of Disease Code, revision 10 (ICD10). From the ERV records, we specifically selected those outpatient visits whose chief complaint was abdominal pain. The research protocol was approved by the Medical Ethics Committee of Zhongnan Hospital. (IRB number: 2021018K) Environmental and meteorological data

We acquired daily ambient air pollution data $\left(\mathrm{SO}_{2}, \mathrm{NO}_{2}, \mathrm{PM}_{2.5}, \mathrm{PM}_{10}, \mathrm{CO}\right.$, and $\left.\mathrm{O}_{3}\right)$ from January 2016 to December 2018, from the website of the Wuhan Ecological Environment Bureau (http://hbj.wuhan.gov.cn/). The daily average concentrations of air pollutant were calculated by average hourly values from ten fixed-site stationary centers, which can cover the urban districts of Wuhan. All the stations are located away from industrial, residential, and vehicle sources, to make sure they can monitor the representative measurements of background pollution, without undue interference. 
The data of two meteorological parameters during the study period (average daily temperature $\left[{ }^{\circ} \mathrm{C}\right]$ and relative humidity [\%]) were acquired from the Meteorological Data Sharing Service System of China Meteorological Administration (Beijing, China). Dates with missing data were eliminated from our study.

\section{Statistical analysis}

We chose the over-dispersed generalized additive model (GAM) to perform a time-series analysis to explore the acute effect of air pollutants on ERVs with abdominal pain, in order to control for both time-invariant and time-varying confounders. Some covariates were added into the main model. First, a natural cubic regression smoothing function of calendar time with 7 degrees of freedom (df) per year excluded unmeasured long-term and seasonal trends longer than two months.(Chen, Lin et al. 2018) Second, a natural smooth function of the average daily temperature (6 df) and

relative humidity ( $3 \mathrm{df}$ ) controlled for the nonlinear confounding effects of weather conditions.(Zhou, Geng et al. 2021) Third, other covariates such as day of the week (DOW) and public holidays (Holiday) were controlled as dummy variables in the basic models.

The core model can be described as follows:

$\log E(Y t)=\beta Z t+D O W+n s($ time,$d f)+n s($ temperature, 6$)+n s($ humidity, 3$)+$ intercept

where $\mathrm{E}(\mathrm{Yt})$ represents the number of abdominal pain count for day $\mathrm{t}$; $\beta$ represents the log-related rate of EVRs with abdominal pain associated with a unit increase of air pollutants; Zt refers to the pollutant concentrations at day $t$; DOW is a dummy variable for day of the week; and ns() means the natural cubic regression smooth function. We plotted the exposure-response relationship curves between air pollutant and ERVs with abdominal pain by adding to the above model a spline function with $3 \mathrm{df}$.

We conducted 4 sensitivity analyses to ensure the stability of our models. First, Two-pollutant models can examine the robustness of effect estimates. Co-pollutants with a correlation coefficient $<0.7$ would be added to the model. Second, we conducted two different lag constructions: single-day lags (lag0 to lag7), and moving average lags (lag 01 to lag 07). Third, we selected alternative df with 4-10 per year. Besides, since air pollution levels vary by season,(Wang, Wang et al. 2018) we divided our analyses into the cool period (October to March) and the warm period (April to September), and reduced the df per year from 7 year-round to 4 in the cool-period and warm-period analyses.

All statistical models were run in R software (version 3.6.0) using the MGCV package. The statistical tests were twosided, with correlations with $\mathrm{p}<0.05$ mean statistically significant. The effects are described as the percent changes and $95 \% \mathrm{Cl}$ in daily ERVs for abdominal pain per $10 \mu \mathrm{g} / \mathrm{m}^{3}$ increase of each pollutant.

\section{Result}

We obtained data from 152,830 ERVs in Zhongnan Hospital (from January 1, 2016 to December 31, 2018), among which 16,306 were caused by abdominal pain. Females and younger people (< 45 years old) constituted respectively $52.5 \%$ and $58.2 \%$ of the visits. Total ERVs for abdominal pain were slightly higher in the warm seasons than in the cool seasons (8331 vs. 7975). The means of daily temperature and relative humidity were $17.87^{\circ} \mathrm{C}$ and $74.99 \%$, respectively. (Table 1) Daily average concentrations were $9.42 \mu \mathrm{g} / \mathrm{m}^{3}$ for $\mathrm{SO}_{2}, 58.89 \mu \mathrm{g} / \mathrm{m}^{3}$ for $\mathrm{NO}_{2}, 68.71 \mu \mathrm{g} / \mathrm{m}^{3}$ for $\mathrm{PM}_{2.5}, 64.8 \mu \mathrm{g} / \mathrm{m}^{3}$ for $\mathrm{PM}_{10}, 25.06 \mu \mathrm{g} / \mathrm{m}^{3}$ for $\mathrm{CO}$ and $48.4 \mu \mathrm{g} / \mathrm{m}^{3}$ for $\mathrm{O}_{3}$. During our study period, there were 382 (24.8\%) and 229 (20.9\%) days respectively where $\mathrm{PM}_{2.5}$ and $\mathrm{NO}_{2}$ exceeded Chinese secondary ambient air quality standards. Other pollutants were within this standard range most of time. 
Table 1

The summary of daily air pollutants, weather conditions, and daily emergency room visit for abdominal pain ( $N=$ 16,306) during our study period (January 1, 2016 to December 31, 2018)

\begin{tabular}{|c|c|c|c|c|c|c|c|}
\hline & Mean & SD & Min & P25 & Median & P75 & Max \\
\hline \multirow{2}{*}{\multicolumn{8}{|c|}{$\begin{array}{l}\text { Air pollutant } \\
\text { concentration }(\mu \mathrm{g} / \mathrm{m} 3)^{a}\end{array}$}} \\
\hline & & & & & & & \\
\hline $\mathrm{SO}_{2}$ & 9.42 & 5.33 & 2.7 & 5.5 & 7.9 & 12.03 & 35.67 \\
\hline $\mathrm{NO}_{2}$ & 58.89 & 22.68 & 17.5 & 40.4 & 56.16 & 75.92 & 122.5 \\
\hline $\mathrm{PM}_{2.5}$ & 68.71 & 39.47 & 9.9 & 41.08 & 60.63 & 86.53 & 254.7 \\
\hline $\mathrm{PM}_{10}$ & 64.8 & 28.17 & 8.6 & 48.3 & 63 & 79 & 461.5 \\
\hline $\mathrm{CO}$ & 25.06 & 7.49 & 8.9 & 19.8 & 23.8 & 29.3 & 59.3 \\
\hline $\mathrm{O}_{3}$ & 48.4 & 31.52 & 2.1 & 24.8 & 39.8 & 67.3 & 190 \\
\hline \multicolumn{8}{|l|}{ Meteorological measures } \\
\hline Temperature $\left({ }^{\circ} \mathrm{C}\right)$ & 17.87 & 9.31 & -4 & 10 & 18.89 & 25.98 & 35.42 \\
\hline Humidity (\%) & 74.99 & 13.38 & 36 & 65.25 & 75.75 & 85.5 & 100 \\
\hline No. of emergency room visit for abdominal pain & 15 & 8 & 1 & 9 & 13 & 20 & 42 \\
\hline \multicolumn{8}{|l|}{ Season(N) } \\
\hline Warm b & 15 & 8 & 1 & 9 & 13 & 20 & 42 \\
\hline $\mathrm{Cool}^{\mathrm{c}}$ & 15 & 7 & 1 & 8 & 13 & 20 & 37 \\
\hline \multicolumn{8}{|l|}{ Gender(N) } \\
\hline Male & 7 & 4 & 0 & 4 & 6 & 10 & 25 \\
\hline Female & 8 & 4 & 0 & 5 & 7 & 11 & 25 \\
\hline \multicolumn{8}{|l|}{$\operatorname{Age}(\mathbf{N})$} \\
\hline$<45$ & 9 & 5 & 0 & 5 & 8 & 12 & 31 \\
\hline
\end{tabular}

a24-hour average for $\mathrm{PM}_{2.5}, \mathrm{PM}_{10}, \mathrm{SO}_{2}$, and $\mathrm{NO}_{2}$; maximal 8-h average for $\mathrm{O}_{3}$

b Warm season: from April to September.

${ }^{\mathrm{c}}$ Cool season: from October to March.

Abbreviations: SD, standard deviation; $\mathrm{P} 25$, 25th percentile; $\mathrm{P} 75$, 75th percentile;

$\mathrm{PM}_{2.5}$, particulate matter with an aerodynamic diameter less than or equal to $2.5 \mu \mathrm{m}$;

$\mathrm{PM}_{10}$, particulate matter with an aerodynamic diameter less than or equal to $10 \mu \mathrm{m}$;

$\mathrm{O}_{3}$, ozone; $\mathrm{SO}_{2}$, sulfur dioxide; $\mathrm{NO}_{2}$, nitrogen dioxide; $\mathrm{CO}$, carbon monoxide. 


\begin{tabular}{|c|c|c|c|c|c|c|c|}
\hline & Mean & SD & Min & P25 & Median & P75 & Max \\
\hline$\geq 45$ & 6 & 4 & 0 & 3 & 6 & 8 & 24 \\
\hline \multicolumn{8}{|c|}{ a24-hour average for $\mathrm{PM}_{2.5}, \mathrm{PM}_{10}, \mathrm{SO}_{2}$, and $\mathrm{NO}_{2}$; maximal 8-h average for $\mathrm{O}_{3}$} \\
\hline \multicolumn{8}{|c|}{ b Warm season: from April to September. } \\
\hline \multicolumn{8}{|c|}{${ }^{\mathrm{c}}$ Cool season: from October to March. } \\
\hline \multicolumn{8}{|c|}{ Abbreviations: SD, standard deviation; P25, 25th percentile; P75, 75th percentile; } \\
\hline \multicolumn{8}{|c|}{$\mathrm{PM}_{2.5}$, particulate matter with an aerodynamic diameter less than or equal to $2.5 \mu \mathrm{m}$; } \\
\hline \multicolumn{8}{|c|}{$\mathrm{PM}_{10}$, particulate matter with an aerodynamic diameter less than or equal to $10 \mu \mathrm{m}$; } \\
\hline $\mathrm{O}_{3}, \mathrm{OZ}$ & e; $\mathrm{CO}, \mathrm{c}$ & bon & xide. & & & & \\
\hline
\end{tabular}

Generally, there were moderate to strong positive correlations between the six pollutants (Spearman's correlation coefficient ranged from 0.55 to 0.87 , Fig. 2) except for $\mathrm{O}_{3}$, which showed weak correlations with other pollutants (-0.260.09). Humidity and temperature were mostly negatively correlated with these pollutants $(-0.46-0.01)$.

Figure 3 presents the percent change in abdominal pain ERVs per $10 \mu \mathrm{g} / \mathrm{m}^{3}$ increase of pollutants concentration, while using different single day lag (lag1-lag7) and multiple-day lags (lag01-lag07). Overall, we found statistically significant relationships between $\mathrm{CO}, \mathrm{O}_{3}$ and abdominal pain ERVs, while other pollutants showed positive but insignificant correlations. Lag01 for $\mathrm{SO}_{2}$ and $\mathrm{O}_{3}$, lag06 for $\mathrm{NO}_{2}, \mathrm{PM}_{10}$ and $\mathrm{CO}$, and lag07 for $\mathrm{PM}_{2.5}$ produced the largest estimates. $10 \mu \mathrm{g} / \mathrm{m}^{3}$ increases of $\mathrm{SO}_{2}, \mathrm{NO}_{2}, \mathrm{PM}_{2.5}, \mathrm{PM}_{10}$, and $\mathrm{O}_{3}$ were correlated respectively with incremental increases in daily ERVs for abdominal pain of $6.12 \%$ (95\% Cl: $-0.44-13.12), 1.65 \%(95 \% \mathrm{Cl}:-0.25-3.59), 1.12 \%(95 \% \mathrm{Cl}$ : $-0.18-2.44), 0.38 \%$ (95\%Cl: $-1.09-1.87), 9.87 \%$ (95\% Cl:3.14-17.05) and 1.11\% (95\%Cl:0.03-2.21). (Table S1)

The exposure-response (E-R) curves for the correlations between pollutants at their peak lag day and abdominal pain ERVs were generally positive (Fig. 4). The E-R curve of $\mathrm{SO}_{2}$ showed a slowly growing slope. The E-R curves of $\mathrm{NO}_{2}$ and CO increased sharply before the concentrations $\geq 50 \mu \mathrm{g} / \mathrm{m}^{3}$ and $\geq 20 \mu \mathrm{g} / \mathrm{m}^{3}$ respectively, and then showed just a slight rise. The E-R curve of $\mathrm{PM}_{2.5}$ was nearly J-shaped, increasing sharply at the concentrations $\leq 50 \mu \mathrm{g} / \mathrm{m}^{3}$ and $\geq$ $100 \mu \mathrm{g} / \mathrm{m}^{3}$. The E-R curves of $\mathrm{PM}_{10}$ and $\mathrm{O}_{3}$ were rising slopes at concentrations $\leq 60 \mu \mathrm{g} / \mathrm{m}^{3}$ and $\leq 100 \mu \mathrm{g} / \mathrm{m}^{3}$ respectively, then became flat.

Table 2 summarizes the results for possible effects modified by season, gender and age. It shows that $\mathrm{PM}_{2.5}$ and $\mathrm{PM}_{10}$ were significantly related to abdominal pain ERVs in cool seasons while CO was significantly related in warm seasons. $\mathrm{A} 10 \mu \mathrm{g} / \mathrm{m}^{3}$ increase of $\mathrm{PM}_{2.5}$ and $\mathrm{PM}_{10}$ in cool seasons corresponded respectively to $1.70 \%$ (95\% Cl: $0.16-$ $3.26)$ and $2.41 \%(95 \% \mathrm{Cl}: 0.21-4.66)$ increases in ERVs, while in warm seasons, it related to $1.20 \%$ and $0.63 \%$ increases, respectively $(\mathrm{P}<0.05)$. By contrast, a $10 \mu \mathrm{g} / \mathrm{m}^{3}$ increase of $\mathrm{CO}$ in warm seasons corresponded to a $20.82 \%$ incremental increase of ERVs (95\% Cl: 6.59-36.95), compared to 5.63\% increments in cool seasons $(P<0.05)$. The influence of $\mathrm{SO}_{2}$ and $\mathrm{O}_{3}$ were more obvious on females than on males (13.65\% vs. $-2.34 \%$; $1.54 \%$ vs. $0.56 \%$, respectively, $\mathrm{P}<0.05$ ). For $\mathrm{CO}$ and $\mathrm{O}_{3}$, the correlations were stronger among younger people ( $<45$ years old) than elders $(10.47 \%$ vs. $0.31 \% ; 1.65 \%$ vs. $0.27 \%$, respectively, $\mathrm{P}<0.05)$. 
Table 2

Percent change $(95 \% \mathrm{Cl})$ in abdominal pain ERVs with a $10 \mu \mathrm{g} / \mathrm{m} 3$ increase in air pollutant concentrations by season, gender and age in Wuhan, China.

\begin{tabular}{|c|c|c|c|c|c|c|}
\hline \multirow[t]{2}{*}{ Pollutants } & \multicolumn{2}{|l|}{ Season } & \multicolumn{2}{|l|}{ Gender } & \multicolumn{2}{|l|}{ Age } \\
\hline & Cool & Warm & Male & Female & Younger & Elder \\
\hline \multirow{2}{*}{$\mathrm{SO}_{2}^{\mathrm{a}}$} & 0.71 & 8.49 & -2.34 & 13.65 & 4.71 & 7.16 \\
\hline & $(-0.44,1.88)$ & $(-5.65,24.74)$ & $(-10.76,6.88)$ & $\begin{array}{l}(4.56,23.53) \\
\star\end{array}$ & $(-3.94,14.14)$ & $(-2.08,17.28)$ \\
\hline \multirow{2}{*}{$\mathrm{NO}_{2}^{\mathrm{b}}$} & -0.01 & 1.25 & 1.97 & 1.29 & 2.18 & 0.95 \\
\hline & $(-2.62,2.67)$ & $(-2.25,4.88)$ & $(-0.59,4.59)$ & $(-1.07,3.70)$ & $(-0.25,4.68)$ & $(1.60,3.57)$ \\
\hline \multirow{2}{*}{$\mathrm{PM}_{2.5}{ }^{\mathrm{c}}$} & 1.70 & 1.20 & 1.54 & 1.06 & 1.52 & 0.97 \\
\hline & $(0.16,3.26)$ * & $(-2.15,4.66)$ & $(-0.21,3.32)$ & $(-0.55,2.69)$ & $(-0.15,3.23)$ & $(-0.76,2.73)$ \\
\hline \multirow[t]{2}{*}{$\mathrm{PM}_{10} \mathrm{~b}$} & 2.41 & 0.63 & 0.98 & 1.35 & 1.40 & 0.98 \\
\hline & $(0.21,4.66) *$ & $(-1.86,3.18)$ & $(-0.99,2.99)$ & $(-0.44,3.18)$ & $(-0.46,3.29)$ & $(-0.99,2.99)$ \\
\hline \multirow[t]{2}{*}{$\mathrm{CO} b$} & 5.63 & 20.82 & 4.85 & 7.06 & 10.47 & 0.31 \\
\hline & $(-2.22,14.12)$ & $(6.59,36.95)$ & $(-3.75,14.21)$ & $(-1.06,15.85)$ & $(1.85,19.83)$ & $(-7.92,9.27)$ \\
\hline \multirow[t]{2}{*}{$\mathrm{O}_{3}{ }^{\mathrm{a}}$} & 1.13 & 1.13 & 0.56 & 1.54 & 1.65 & 0.27 \\
\hline & $(-1.45,3.77)$ & $(-1.45,3.77)$ & $(-0.92,2.06)$ & $(0.16,2.93)$ * & $(0.26,3.05)$ * & $(-1.25,1.82)$ \\
\hline \multicolumn{7}{|l|}{$\star p<0.05$} \\
\hline \multicolumn{7}{|c|}{ a Moving average of lag 01 was used for $\mathrm{SO}_{2}$, and $\mathrm{O}_{3}$. } \\
\hline \multicolumn{7}{|c|}{ b Moving average of lag 06 were used for $\mathrm{NO}_{2}, \mathrm{PM}_{10}$ and $\mathrm{CO}$. } \\
\hline${ }^{c}$ Moving a & rage of lag 07 & s used for $\mathrm{PI}$ & & & & \\
\hline
\end{tabular}

Pollutants with < 0.7 Spearman correlation co-efficient were added into two-pollutant models, and most models remained stable after adjusting for co-pollutants. Especially for $\mathrm{CO}$, its positive relation with daily ERVs for abdominal pain remained significantly robust after adjustment (Table 3). Another sensitivity analysis proved that alternative $d f$ (4-10) did not significantly affect the effects of pollutants on abdominal pain ERVs (Figure S1). 
Table 3

Percent change $(\%$, mean and $95 \% \mathrm{CI})$ in ERVs for abdominal pain in two-pollutant models.

\begin{tabular}{|c|c|c|}
\hline \multicolumn{2}{|c|}{ Two-pollutants } & \multirow{2}{*}{$\begin{array}{l}\text { Estimate } \\
6.12(-0.44,13.12)\end{array}$} \\
\hline $\mathrm{SO}_{2}$ & - & \\
\hline & $+\mathrm{PM}_{2.5}$ & $5.67(-1.55,13.43)$ \\
\hline & $+\mathrm{CO}$ & $4.92(-2.52,12.93)$ \\
\hline & $+\mathrm{O}_{3}$ & $4.66(-2.22,12.02)$ \\
\hline \multirow[t]{4}{*}{$\mathrm{NO}_{2}$} & - & $1.65(-0.25,3.59)$ \\
\hline & $+\mathrm{PM}_{2.5}$ & $1.13(-1.12,3.43)$ \\
\hline & $+\mathrm{CO}$ & $0.39(-1.71,2.53)$ \\
\hline & $+\mathrm{O}_{3}$ & $1.32(-0.80,3.49)$ \\
\hline \multirow[t]{4}{*}{$\mathrm{PM}_{2.5}$} & - & $1.12(-0.18,2.44)$ \\
\hline & $+\mathrm{SO}_{2}$ & $1.00(-0.50,2.52)$ \\
\hline & $+\mathrm{NO}_{2}$ & $0.85(-0.70,2.43)$ \\
\hline & $+\mathrm{O}_{3}$ & $0.96(-0.45,2.39)$ \\
\hline \multirow[t]{2}{*}{$\mathrm{PM}_{10}$} & - & $0.38(-1.09,1.87)$ \\
\hline & $+\mathrm{O}_{3}$ & $-0.24(-1.87,1.41)$ \\
\hline \multirow[t]{5}{*}{$\mathrm{CO}$} & - & $9.87(3.14,17.05)$ * \\
\hline & $+\mathrm{SO}_{2}$ & $10.10(3.01,17.68)$ * \\
\hline & $+\mathrm{NO}_{2}$ & $9.47(2.00,17.48)$ * \\
\hline & $+\mathrm{PM}_{10}$ & $12.40(4.67,20.70)$ * \\
\hline & $+\mathrm{O}_{3}$ & $9.58(2.71,16.92)$ * \\
\hline \multirow[t]{3}{*}{ O3 } & - & $1.11(0.03,2.21)$ * \\
\hline & $+\mathrm{SO}_{2}$ & $0.95(-0.17,2.08)$ \\
\hline & $+\mathrm{NO}_{2}$ & $0.97(-0.16,2.12)$ \\
\hline
\end{tabular}

$* \mathrm{p}<0.05$.
Moving average of lag 01 was used for $\mathrm{SO}_{2}$, and $\mathrm{O}_{3}$.
Moving average of lag 06 were used for $\mathrm{NO}_{2}, \mathrm{PM}_{10}$ and $\mathrm{CO}$.
Moving average of lag 07 was used for $\mathrm{PM}_{2.5}$.




\begin{tabular}{|c|c|}
\hline Two-pollutants & Estimate \\
\hline$+\mathrm{PM}_{2.5}$ & $1.10(-0.07,2.28)$ \\
\hline$+\mathrm{PM}_{10}$ & $1.12(-0.02,2.27)$ \\
\hline$+\mathrm{CO}$ & $0.98(-0.16,2.14)$ \\
\hline \multicolumn{2}{|l|}{$* p<0.05$} \\
\hline \multicolumn{2}{|c|}{ Moving average of lag 01 was used for $\mathrm{SO}_{2}$, and $\mathrm{O}_{3}$. } \\
\hline \multicolumn{2}{|c|}{ Moving average of lag 06 were used for $\mathrm{NO}_{2}, \mathrm{PM}_{10}$ and $\mathrm{CO}$} \\
\hline Moving average of la & ras used for $\mathrm{PM}_{2.5}$. \\
\hline
\end{tabular}

\section{Discussion}

Abdominal pain is one of the most common reason for ERVs (Hooker, Mallow et al. 2019), and few studies have explored the acute effect of ambient air pollution on abdominal pain, especially in emergency room visits. Overall, our study suggests that short-term exposure to air pollutants, including $\mathrm{CO}$ and $\mathrm{O}_{3}$, is significantly correlated with increased risks of abdominal pain ERVs. The correlations between $\mathrm{CO}$ and abdominal pain ERVs was robust after adjustment in two-pollutant models. The correlations were stronger mainly on females (especially $\mathrm{SO}_{2}$ and $\mathrm{O}_{3}$ ) and younger people (especially $\mathrm{CO}$ and $\mathrm{O}_{3}$ ). The correlations of $\mathrm{PM}_{2.5}$ and $\mathrm{PM}_{10}$ were stronger in cool seasons, but for $\mathrm{CO}$ stronger in warm seasons. Our findings have added evidence on how air pollutants affect the human body, and may help hospitals take precaution in polluted days and maintain order in emergency departments made busier due to the pollution.

During our study period, the mean concentrations of $\mathrm{PM}_{2.5}\left(68.71 \mu \mathrm{g} / \mathrm{m}^{3}\right)$ and $\mathrm{NO}_{2}\left(58.89 \mu \mathrm{g} / \mathrm{m}^{3}\right)$ in Wuhan exceeded the Chinese National Ambient Air Quality Standards $\left(35\right.$ and $40 \mu \mathrm{g} / \mathrm{m}^{3}$ ). Urban expansion, industrial development, the increase of motor vehicles, and an aging population are major contributors to the effects of severe pollution. However, it is promising that the overall trend of air quality is improving.(Huang, Pan et al. 2018)

Our study proved that short-term exposure of ambient air pollutants $\left(\mathrm{SO}_{2}, \mathrm{NO}_{2}, \mathrm{PM}_{10}, \mathrm{PM}_{2.5}, \mathrm{CO}, \mathrm{O}_{3}\right)$ have positive correlations with the ERVs for abdominal pain, especially $\mathrm{CO}$ and $\mathrm{O}_{3}$. Highly elevated or protracted $\mathrm{CO}$ exposures may produce untoward biological oxidations, and interfere with homeostasis.(Piantadosi 2008) CO can readily absorbed from the lungs into the bloodstream, forms carboxyhemoglobin with hemoglobin, thus resulting in tissue hypoxia. And the relationships between lipid peroxidation and membrane fatty acid composition in $\mathrm{CO}$ intoxication may be a potential mechanism.(Akyol, Erdogan et al. 2014) The cooperation of $\mathrm{CO}$ and $\mathrm{PM}_{2.5}$ may also enhance the damage which was also showed in our study (the Spearman correlation co-efficient of them $>0.7$ ) but this is still not certain. (Chen, Gokhale et al. 2007) For $\mathrm{O}_{3}$, the toxicity was due mainly to its action as an oxidant, causing lipid peroxide decomposition, and inflammatory and blood rheology.(Mehlman and Borek 1987, Yang, Li et al. 2019) The systemic response may also affect the digestive and urinary systems, and lead to abdominal pain. Although $\mathrm{O}_{3}$ has been regarded as a kind of medical drug gradually, we still suggest more attention to its effect of different concentrations and the particular biological system where it acts.(Zanardi, Borrelli et al. 2016)

The positive results varied also by season, sex, and age. In our study, CO demonstrated a stronger effect in warm seasons than in cool seasons. This may be because of the extremely hot weather from July to September in Wuhan, 
leading to more fluid loss cooperating with $\mathrm{CO}$ and increasing the risk of hypoxia. Vasoconstrictions happen in the digestive and urinary systems, and can result in abdominal pain. Many studies showing ambient pollutants having more serious effect on elders are contrary to our results, which showed that $\mathrm{CO}$ and $\mathrm{O}_{3}$ affected younger people more. (Bell, Zanobetti et al. 2013) Since our study data were from emergency departments, most of the visits with abdominal pain were acute and inflammatory. Younger people usually have more outdoor activities, and thus more chance to ingest pollutants than elders do. Another possible explanation is that the effects on elders center mainly on the cardiovascular system rather than the digestive or urinary systems. We found also that females were more likely to suffer the effects of $\mathrm{SO}_{2}$ and $\mathrm{O}_{3}$ increases. This phenomenon was proved in the respiratory and cardiovascular systems as well.(Tseng, Huang et al. 2012, Birukova, Cyphert-Daly et al. 2019) In our study, $\mathrm{PM}_{2.5}$ and $\mathrm{PM}_{10}$ demonstrated higher effects during cool seasons, which was consistent with previous studies.(Zhang and Cao 2015, Song, Lu et al. 2018) Their studies attributed the correlations to the increase in coal burning in households as the source of heat, and to the unfavorable meteorological conditions in winter, which limit the dispersion of air pollutants. (Zhang and Cao 2015)

However, excessive focus on the effects of a single pollutant may ignore the cooperation between pollutants. Population-based observational studies should consider the correlations between them.(Chen, Gokhale et al. 2007) The exposure-response curves are crucial tools for public health assessment. We did not observe evident threshold concentrations above which $\mathrm{NO}_{2}, \mathrm{PM}_{2.5}$ and $\mathrm{CO}$ were not correlated with ERVs. Interestingly, we observed a J-shaped relationship between $\mathrm{PM}_{2.5}$ and abdominal pain ERVs, which need in future studies to be considered when investigating health effects of $\mathrm{PM}_{2.5}$.

The most common acute diseases in ERVs for abdominal pain are gastroenteritis, cholecystitis, and urolithiasis. The correlations between gastrointestinal diseases and air pollution have been widely discussed in recent years. Studies showed that air pollution exposure may increase the risk of appendicitis, as well as hospitalizations for inflammatory bowel disease, peptic ulcers, and enteritis.(Kaplan, Dixon et al. 2009, Ananthakrishnan, McGinley et al. 2011, Xu, Kan et al. 2016, Tsai, Chiu et al. 2019) A study in Canada found that air pollution may cause non-specific abdominal pain, especially in young ladies, which is consistent with our studies.(Kaplan, Szyszkowicz et al. 2012) The main mechanisms for pollutants increasing gastrointestinal diseases include directly toxic effects, systemic inflammation, immune activation, gut microbiota effects, and gut permeability effects (Beamish, Osornio-Vargas et al. 2011, Mutlu, Engen et al. 2011).

Cholecystitis caused by gallstone is one of the most common diseases in emergency department visits. There have been not studies investigating the correlation between ambient air pollution and cholecystitis at present. Actually, cholecystic diseases have a close relationship with liver diseases but more common than them in emergency department. Studies have revealed that the obstruction of cholecystitis may result in hepatic inflammatory changes and make liver diseases progress to secondary biliary cirrhosis.(Flinn, Olson et al. 1977, Geraghty and Goldin 1994) And chronic liver diseases will impair the gallbladder contractility and contribute to the increased gallstone formation in return.(Acalovschi, Dumitrascu et al. 2004) Long-term exposure to environmental pollutants may lead to liver abnormality or injury by activating reactive oxygen species (ROS) production and initial immune response(SanchezValle, Chavez-Tapia et al. 2012, Kim, Park et al. 2014) which were all chronic effect on liver. As for acute effect, we suppose maybe ambient air pollution also has positive correlation with cholecystitis through causing dyslipidemia(Zhang, Wang et al. 2021) which was considered as a risk factor of gallstones and cholecystitis. (Lammert, Gurusamy et al. 2016) Whether the liver injuries or the cholecystic diseases are the initiating agents for acute hepatobiliary diseases is still uncertain. 
Furthermore, air pollution may increase the risk of bladder, kidney and urinary tract cancer, as well as other more benign diseases.(Al-Aly and Bowe 2020, Zare Sakhvidi, Lequy et al. 2020) In an emergency department, the most common visits for abdominal pain in urinary system are for urolithiasis. The effects of particulate matter can lead to vascular endothelial injury, systemic inflammation, atherosclerosis, and microvascular changes,(Sun, Wang et al. 2005, Chow, Watson et al. 2006) and thus may cause urine volume decreases, which can result in urolithiasis. However, there are as yet no studies examining the correlation between urolithiasis and ambient air pollution, which bears further investigation.

Our study has limitations. First, as in most previous studies, we used fixed-site monitor measurements to represent personal exposure, causing exposure errors. However, the resultant non-differential error was reported to produce an underestimate of the correlations of ambient air pollution.(Samet, Zeger et al. 2000) Second, due to data limitations, we didn't take pre-existing diseases and unhealthy factors into account, either of which may weaken one's tolerance of air pollutants. Third, since our study was conducted only from emergency department data, some visits could not produce a definite diagnosis, or even get a wrong diagnosis, which is hard to avoid. Fourth, this study collected data from only one highly polluted city, thus its general application might be limited.

\section{Conclusions}

Our time-series study suggests that ambient air pollution (especially $\mathrm{CO}$ and $\mathrm{O}_{3}$ ) has a positive correlation with the ERVs for abdominal pain in Wuhan, China. The effects varied by season, gender and age. The estimates of effects from most pollutants on ERVs for abdominal pain were higher among females and younger people. The correlations between $\mathrm{PM}_{2.5}, \mathrm{PM}_{10}$ and ERVs for abdominal pain were stronger in cool seasons while the correlation of $\mathrm{CO}$ was higher in warm seasons. Specifically, we focused more attention on the correlations between ambient air pollution and specific emergency diseases manifested as abdominal pain, and we expect this study can help hospitals to take precaution in polluted days, and improve timely treatment in hospitals.

\section{Declarations}

\section{Ethics approval and consent to participate}

The research protocol was approved by the Medical Ethics Committee of Zhongnan Hospital. (IRB number: 2021018K)

\section{Consent for publication}

Not applicable

\section{Availability of data and materials}

The datasets used and/or analysed during the current study are available from the corresponding author on reasonable request.

\section{Competing interests}

The authors declare that they have no competing interests

\section{Funding}

This work was supported by Zhongnan Hospital of Wuhan University Science, Technology and Innovation Seed Fund, Project znpy2018064. 
Authors' contributions

Yaqi Liu: Methodology, Software, Investigation, Visualization, Writing - Original Draft. Yi Jiang: Writing- Reviewing and Editing. Manyi Wu: Investigation. Sunghar Muheyat: Software, Validation. Dongai Yao: Resources, Xiaoqing Jin: Supervision, Project administration, Funding acquisition.

\section{Acknowledgments}

We would like to thank all the participants who made this study possible.

\section{References}

1. Acalovschi M, Dumitrascu DL, Nicoara CD (2004) "Gallbladder contractility in liver cirrhosis: comparative study in patients with and without gallbladder stones". Dig Dis Sci 49(1):17-24

2. Akyol S, Erdogan S, Idiz N, Celik S, Kaya M, Ucar F, Dane S, Akyol O (2014) The role of reactive oxygen species and oxidative stress in carbon monoxide toxicity: an in-depth analysis. Redox Rep 19(5):180-189

3. Al-Aly Z, Bowe B (2020) "Air Pollution and Kidney Disease". Clin J Am Soc Nephrol 15(3):301-303

4. Al Ahad MA, Sullivan F, Demsar U, Melhem M, Kulu H (2020) "The effect of air-pollution and weather exposure on mortality and hospital admission and implications for further research: A systematic scoping review." Plos One 15(10)

5. Ananthakrishnan AN, McGinley EL, Binion DG, Saeian K (2011) "Ambient Air Pollution Correlates with Hospitalizations for Inflammatory Bowel Disease: An Ecologic Analysis". Inflamm Bowel Dis 17(5):1138-1145

6. Beamish LA, Osornio-Vargas AR, Wine E (2011) Air pollution: An environmental factor contributing to intestinal disease. Journal of Crohns Colitis 5(4):279-286

7. Bell ML, Zanobetti A, Dominici F (2013) "Evidence on Vulnerability and Susceptibility to Health Risks Associated With Short-Term Exposure to Particulate Matter: A Systematic Review and Meta-Analysis". Am J Epidemiol 178(6):865-876

8. Birukova A, Cyphert-Daly J, Cumming RI, Yu YR, Gowdy KM, Que LG, Tighe RM (2019) "Sex Modifies Acute OzoneMediated Airway Physiologic Responses" Toxicol Sci 169(2): 499-510

9. Chen F, Lin Z, Chen R, Norback D, Liu C, Kan H, Deng Q, Huang C, Hu Y, Zou Z, Liu W, Wang J, Lu C, Qian H, Yang X, Zhang X, Qu F, Sundell J, Zhang Y, Li B, Sun Y, Zhao Z (2018) "The effects of PM2.5 on asthmatic and allergic diseases or symptoms in preschool children of six Chinese cities, based on China, Children, Homes and Health (CCHH) project". Environ Pollut 232:329-337

10. Chen TM, Gokhale J, Shofer S, Kuschner WG (2007) Outdoor air pollution: Nitrogen dioxide, sulfur dioxide, and carbon monoxide health effects. Am J Med Sci 333(4):249-256

11. Chen Y, Zheng M, Lv J, Shi T, Liu P, Wu Y, Feng W, He W, Guo P (2019) "Interactions between ambient air pollutants and temperature on emergency department visits: Analysis of varying-coefficient model in Guangzhou. China" Sci Total Environ 668:825-834

12. Chow JC, Watson JG, Mauderly JL, Costa DL, Wyzga RE, Vedal S, Hidy GM, Altshuler SL, Marrack D, Heuss JM, Wolff GT, Pope CA, Dockery DW (2006) Health effects of fine particulate air pollution: Lines that connect. J Air Waste Manag Assoc 56(10):1368-1380

13. Collaborators GBDRF (2018) Global, regional, and national comparative risk assessment of 84 behavioural, environmental and occupational, and metabolic risks or clusters of risks for 195 countries and territories, 19902017: a systematic analysis for the Global Burden of Disease Study 2017. Lancet 392(10159):1923-1994

Page $12 / 18$ 
14. Flinn WR, Olson DF, Oyasu R, Beal JM (1977) "Biliary bacteria and hepatic histopathologic changes in gallstone disease". Ann Surg 185(5):593-597

15. Geraghty JM, Goldin RD (1994) "Liver changes associated with cholecystitis". J Clin Pathol 47(5):457-460

16. Gu J, Shi Y, Zhu Y, Chen N, Wang H, Zhang Z, Chen T (2020) Ambient air pollution and cause-specific risk of hospital admission in China: A nationwide time-series study. PLoS Med 17(8):e1003188

17. Hooker EA, Mallow PJ, Oglesby MM (2019) "Characteristics and Trends of Emergency Department Visits in the United States (2010-2014)". J Emerg Med 56(3):344-351

18. Huang J, Pan XC, Guo XB, Li GX (2018) Health impact of China's Air Pollution Prevention and Control Action Plan: an analysis of national air quality monitoring and mortality data. Lancet Planetary Health 2(7):E313-E323

19. Kaplan GG, Dixon E, Panaccione R, Fong A, Chen L, Szyszkowicz M, Wheeler A, MacLean A, Buie WD, Leung T, Heitman SJ, Villeneuve PJ (2009) Effect of ambient air pollution on the incidence of appendicitis. Can Med Assoc J 181(9):591-597

20. Kaplan GG, Szyszkowicz M, Fichna J, Rowe BH, Porada E, Vincent R, Madsen K, Ghosh S, Storr M (2012) "NonSpecific Abdominal Pain and Air Pollution: A Novel Association." Plos One 7(10)

21. Kim JW, Park S, Lim CW, Lee K, Kim B (2014) "The role of air pollutants in initiating liver disease". Toxicol Res 30(2):65-70

22. Lammert F, Gurusamy K, Ko CW, Miquel JF, Méndez-Sánchez N, Portincasa P, van Erpecum KJ, van Laarhoven CJ, Wang DQ (2016) "Gallstones" Nat Rev Dis Primers 2:16024

23. Mehlman MA, Borek C (1987) Toxicity and biochemical mechanisms of ozone. Environ Res 42(1):36-53

24. Mutlu EA, Engen PA, Soberanes S, Urich D, Forsyth CB, Nigdelioglu R, Chiarella SE, Radigan KA, Gonzalez A, Jakate S, Keshavarzian A, Budinger GRS, Mutlu GM (2011) "Particulate matter air pollution causes oxidant-mediated increase in gut permeability in mice." Particle and Fibre Toxicology 8

25. Piantadosi CA (2008) Carbon monoxide, reactive oxygen signaling, and oxidative stress. Free Radic Biol Med 45(5):562-569

26. Ren M, Li N, Wang Z, Liu Y, Chen X, Chu Y, Li X, Zhu Z, Tian L, Xiang H (2017) "The short-term effects of air pollutants on respiratory disease mortality in Wuhan, China: comparison of time-series and case-crossover analyses. " Sci Rep 7:40482

27. Rodopoulou S, Samoli E, Chalbot MG, Kavouras IG (2015) "Air pollution and cardiovascular and respiratory emergency visits in Central Arkansas: A time-series analysis". Sci Total Environ 536:872-879

28. Samet JM, Zeger SL, Dominici F, Curriero F, Coursac I, Dockery DW, Schwartz J, Zanobetti A (2000) "The National Morbidity, Mortality, and Air Pollution Study. Part II: Morbidity and mortality from air pollution in the United States. " Res Rep Health Eff Inst 94(Pt 2):5-70; discussion 71-79

29. Sanchez-Valle V, Chavez-Tapia NC, Uribe M, Mendez-Sanchez N (2012) "Role of Oxidative Stress and Molecular Changes in Liver Fibrosis: A Review". Curr Med Chem 19(28):4850-4860

30. Song J, Lu M, Zheng L, Liu Y, Xu P, Li Y, Xu D, Wu W (2018) "Acute effects of ambient air pollution on outpatient children with respiratory diseases in Shijiazhuang, China". BMC Pulm Med 18(1):150

31. Sun QH, Wang AX, Jin XM, Natanzon A, Duquaine D, Brook RD, Aguinaldo JGS, Fayad ZA, Fuster V, Lippmann M, Chen LC, Rajagopalan S (2005) Long-term air pollution exposure and acceleration of atherosclerosis and vascular inflammation in an animal model. Jama-Journal of the American Medical Association 294(23):3003-3010

32. Tsai SS, Chiu HF, Yang CY (2019) "Ambient Air Pollution and Hospital Admissions for Peptic Ulcers in Taipei: A Time-Stratified Case-Crossover Study." International Journal of Environmental Research and Public Health 16(11) 
33. Tseng CY, Huang YC, Su SY, Huang JY, Lai CH, Lung CC, Ho CC, Liaw YP (2012) "Cell type specificity of female lung cancer associated with sulfur dioxide from air pollutants in Taiwan: an ecological study". BMC Public Health $12: 4$

34. Vignal C, Guilloteau E, Gower-Rousseau C, Body-Malapel M (2021) "Review article: Epidemiological and animal evidence for the role of air pollution in intestinal diseases." Science of the Total Environment 757

35. Wang XY, Wang WC, Jiao SL, Yuan J, Hu CP, Wang L (2018) The effects of air pollution on daily cardiovascular diseases hospital admissions in Wuhan from 2013 to 2015. Atmos Environ 182:307-312

36. Xu C, Kan HD, Fan YN, Chen RJ, Liu JH, Li YF, Zhang Y, Ji AL, Cai TJ (2016) "Acute effects of air pollution on enteritis admissions in Xi'an. China" Journal of Toxicology Environmental Health-Part a-Current Issues 79(24):1183-1189

37. Yang H, Li N, Han J, Zhu CL, Tian L, Lin BC, Xi ZG, Liu XH, Chu N (2019) [Injury of rat blood vessels caused by acute ozone exposure and its mechanism]. Zhongguo Ying Yong Sheng Li Xue Za Zhi 35(3):193-198

38. Zanardi I, Borrelli E, Valacchi G, Travagli V, Bocci V (2016) "Ozone: A Multifaceted Molecule with Unexpected Therapeutic Activity". Curr Med Chem 23(4):304-314

39. Zare Sakhvidi MJ, Lequy E, Goldberg M, Jacquemin B (2020) "Air pollution exposure and bladder, kidney and urinary tract cancer risk: A systematic review. " Environ Pollut 267:115328

40. Zhang K, Wang H, He W, Chen G, Lu P, Xu R, Yu P, Ye T, Guo S, Li S, Xie Y, Hao Z, Wang H, Guo Y (2021) "The association between ambient air pollution and blood lipids: A longitudinal study in Shijiazhuang. China" Sci Total Environ 752:141648

41. Zhang Y-L, Cao F (2015) Fine particulate matter (PM 2.5) in China at a city level. Scientific reports 5:1488414884

42. Zhou H, Geng H, Dong C, Bai T (2021) The short-term harvesting effects of ambient particulate matter on mortality in Taiyuan elderly residents: A time-series analysis with a generalized additive distributed lag model. Ecotoxicol Environ Saf 207:111235

\section{Figures}




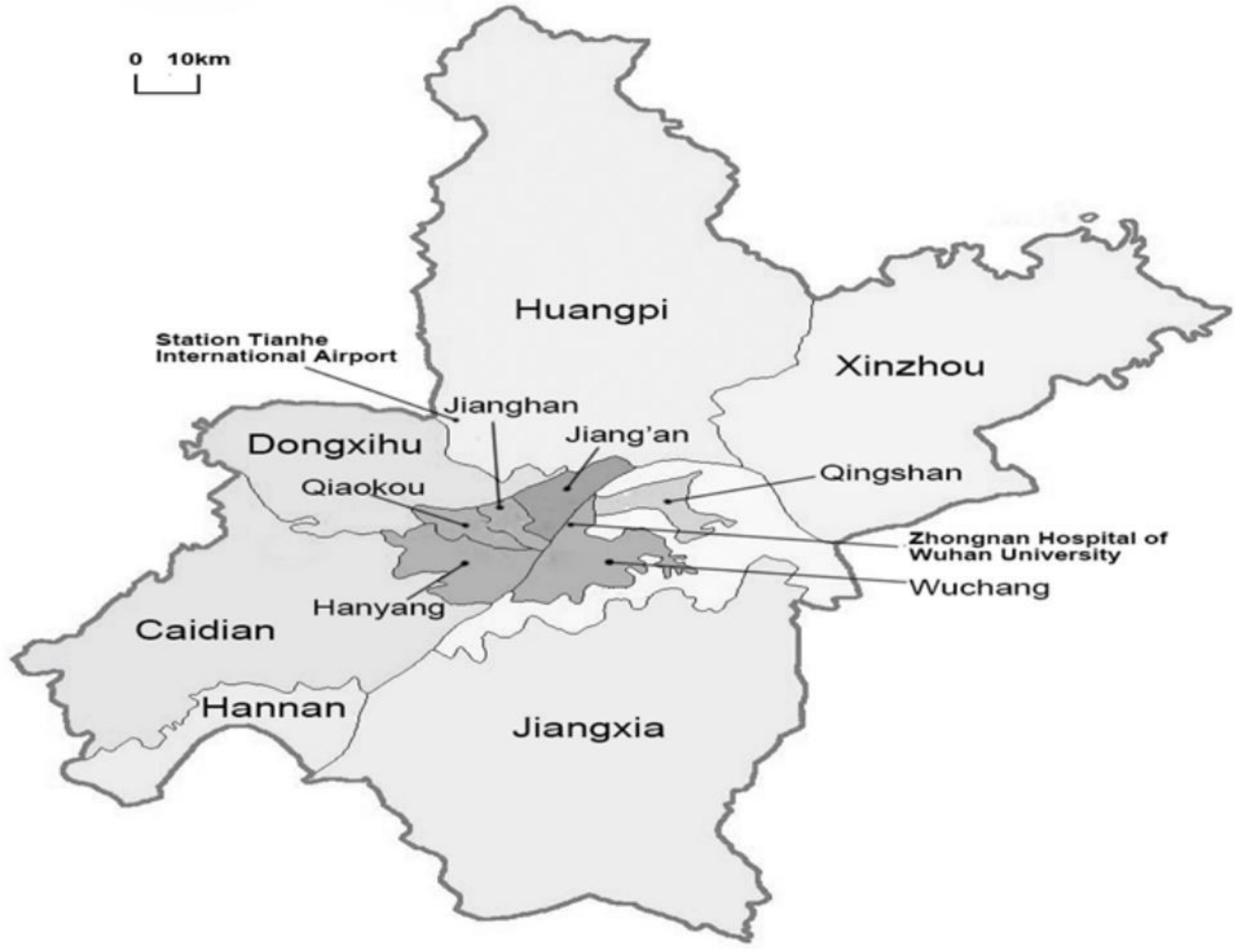

Figure 1

Wuhan (shaded area is the urban area) 


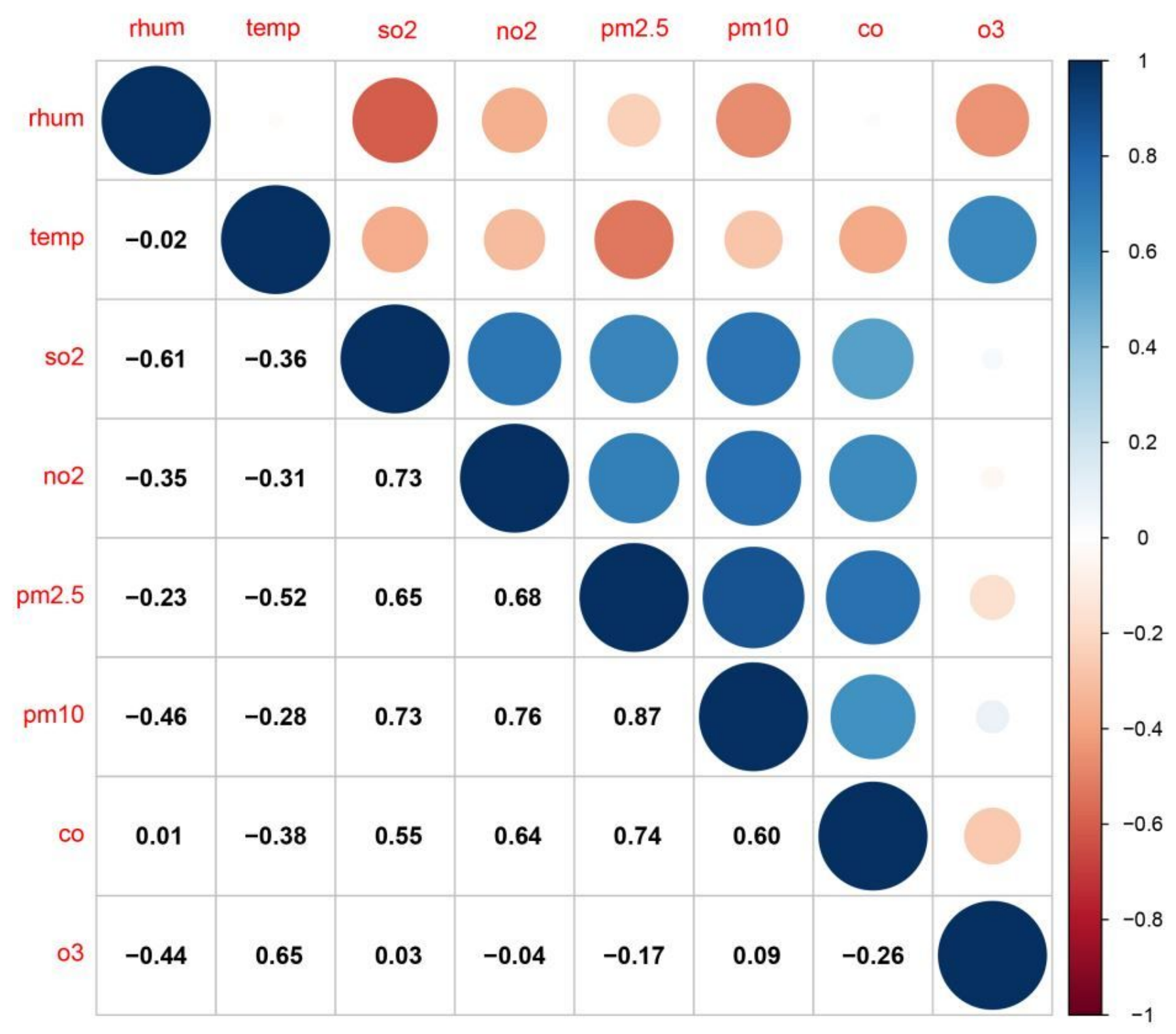

Figure 2

Spearman correlations among exposure variables in Wuhan, China (2016-2018). temp, Temperature; rhum, Relative Humidity 


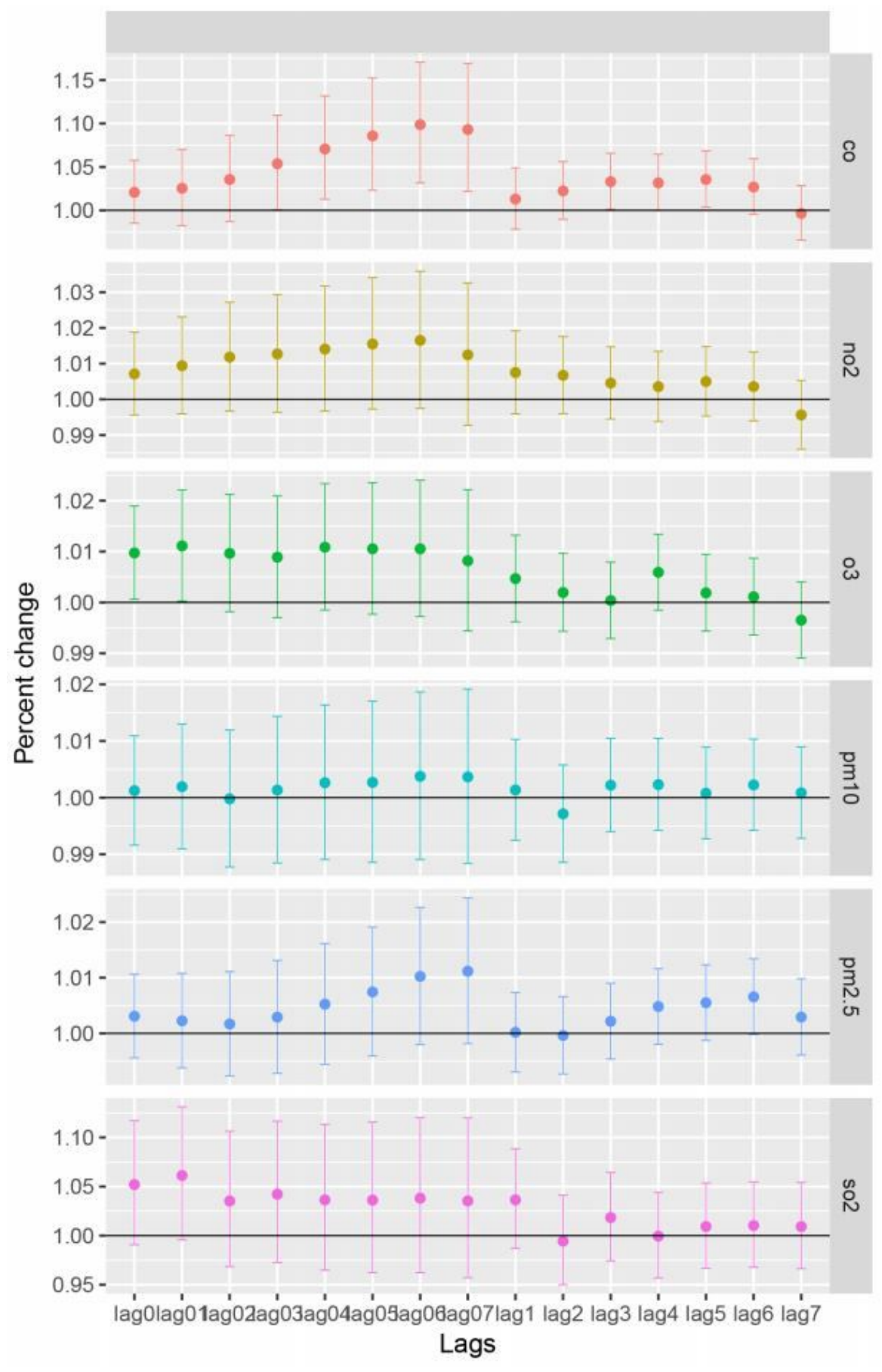

\section{Figure 3}

Percentage change (\%) of ERVs for abdominal pain (mean and 95\% $\mathrm{Cl}$ ) associated with a $10 \mu \mathrm{g} / \mathrm{m} 3 \mathrm{increase}$ in various air pollutant concentrations using different lag structures 
The exposure-response(E-R) curves
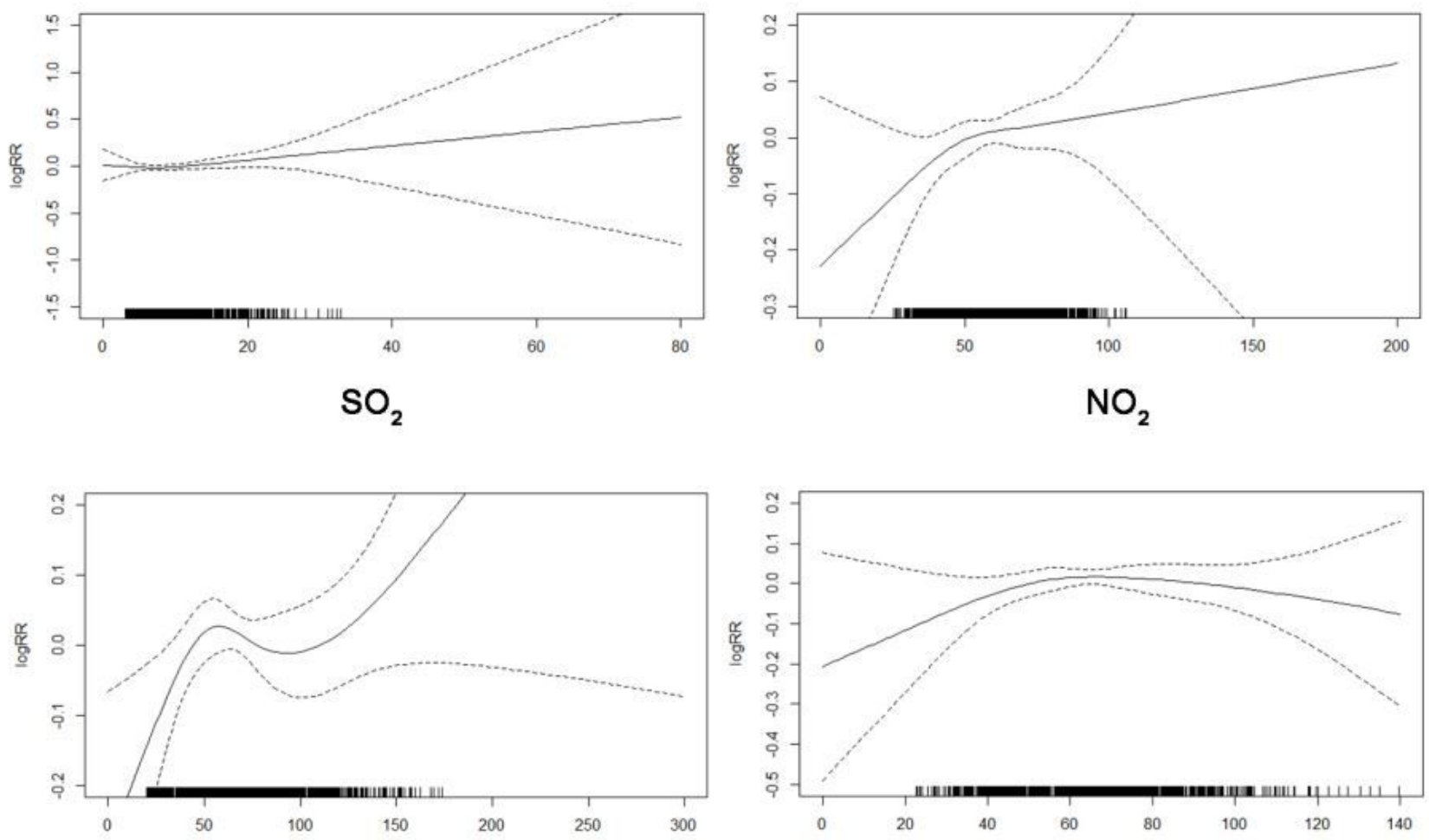

$\mathrm{PM}_{2.5}$
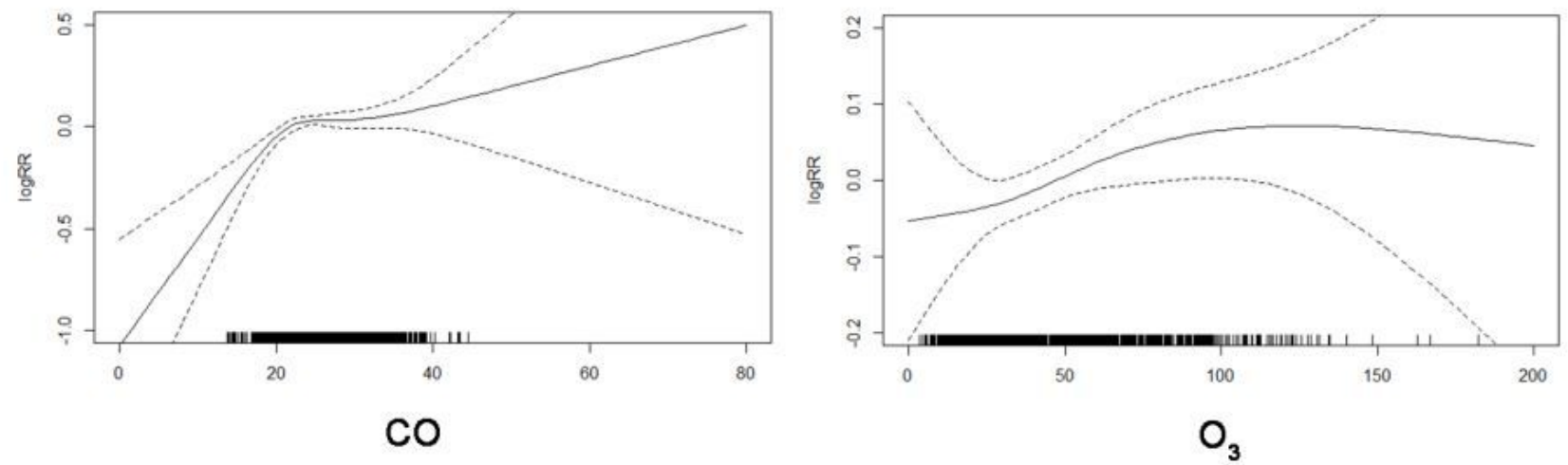

Figure 4

The exposure-response relationship curves of SO2 (lag01), NO2 (lag06), PM2.5 (lag07), PM 10 (lag06), CO (lag06) and 03 (lag01)

\section{Supplementary Files}

This is a list of supplementary files associated with this preprint. Click to download.

- Fig.S1.pdf

- supplementaryfile.docx 